\title{
La vertiente antropofágica de Ferreira Gullar
}

\section{Anthropophagic approach on Ferreira Gullar}

\author{
Diana Araujo Pereira ${ }^{1}$ \\ Universidad Federal de la Integración Latinoamericana (Unila), Foz do Iguaçu, Brasil \\ diana.pereira@unila.edu.br
}

\section{RESUMEN}

Este trabajo tiene por objetivo acercar la poética del brasileño Ferreira Gullar a una vertiente de la poesía crítica muy productiva en América Latina, que está involucrada en los procesos sociohistóricos del continente, y en particular a la poética del peruano Antonio Cisneros. También busca vincular ambas poéticas a toda una genealogía derivada de los proyectos vanguardistas de Brasil y el Perú, a través de una breve incursión por la antropofagia.

\section{PALABRAS CLAVE}

Poesía latinoamericana, Ferreira Gullar, Antonio Cisneros, vanguardias, antropofagia

\section{ABSTRACT}

The main objective of this paper is to put in evidence the anthopophagic approach of the Brazilian poetic Ferreira Gullar, a very critic and productive in Latin America, and also involved in social historical process in the region as the Peruvian poetic Antonio Cisneros. This work also tried to put together from both poetics a entire genealogy derived from Brazilian and Peruvian vanguard, following a brief anthropophagic road.

1 Diana Araujo Pereira es profesora de Literatura Latinoamericana de la Universidad Federal de la Integración Latinoamericana (Unila). Es graduada en Letras por la Universidad Federal de Río de Janeiro (UFRJ) (1998), magíster en Lengua e Literaturas Hispánicas (2002) y doctora en Literaturas Hispánicas también por la UFRJ, con periodo de pasantía doctoral en la Universidad de Sevilla (2007). De 2008 a 2010 realizó su posdoctorado en la UFRJ (ProdocCapes). Es docente del Máster Interdisciplinario en Estudios Latinoamericanos (IELA-Unila). También es traductora y poeta. Actualmente se desempeña como presidente de la Asociación Brasileña de Hispanistas (2014-2016) y lidera el grupo de investigación «Construcciones socioculturales de la Triple Frontera». Entre sus publicaciones destacan Cartografia imaginária da Tríplice Fronteira (Dobra, 2014) e Imaginários coloniais: continuidades e rupturas na América Latina contemporânea (Dobra, 2015). Sus áreas de pesquisa son: crítica cultural, poesía latinoamericana contemporánea, geopoética e interculturalidad. 


\section{KEYWORDS}

Latin American poetry, Ferreira Gullar, Antonio Cisneros, Vanguards, anthropophagic

\section{Antropofagia}

Ferreira Gullar (Brasil, 1930) se inscribe en una pléyade de escritores de América Latina que sostiene, a través de su obra, una poética que se erige sobre la potencia de la crítica político-social, y que cree en la capacidad transformadora de la palabra poética. En su quehacer literario, el rol del escritor —o la función social del arte- son siempre temas de reflexión tanto lírica como ensayística.

Gullar se incluye en el gran mosaico que integra distintas voces de la lírica latinoamericana, como heredero de muchas de las discusiones históricas e identitarias desarrolladas por el movimiento antropofágico y las reflexiones «macunaímicas» de Mário de Andrade y del modernismo brasileño ${ }^{2}$, de carácter más explícitamente paródico e irónico, respecto a los movimientos de vanguardia del continente.

Este poeta, por tanto, se une a otras voces, sumándose a la hermandad poética ${ }^{3}$ fomentadora de una cartografía intrínsecamente latinoamericana, cuyo discurso avanza un presente que mira hacia el futuro, pero sin dejar de sostenerse sobre un pasado en cuyas raíces profundizan nuevas identidades fuertemente vinculadas al espacio y al tiempo hecho territorio común de transformaciones sociales y de las subjetividades (Santos, 2009); es decir, Ferreira Gullar forma parte de esta cartografía poética que se levanta sobre un discurso literario que busca sumergirse tanto en el presente como en el pasado, con el objetivo de mover las fuerzas del imaginario colectivo; cuestionando, entre otras cosas, la hegemonía de las matrices europeas del pensar, del sentir y del imaginar.

Según Rodríguez Monegal, desde el barroco los modelos importados e impuestos por la cultura oficial eran inmediatamente parodiados, exacerbados, y «la entronización y la destronización de las ideologías eran practicados con toda celeridad» (Rodríguez Monegal, 1979, p. 406). Sus herederos vanguardistas, en la década de 1920, elaborarían una suerte de «espíritu de época» que cundía por todo el continente; entre ellos, la antropofagia brasileña:

2 Recuérdese que el «modernismo» brasileño equivale a los movimientos de vanguardia en la América hispánica.

3 Ver Pereira, D. A. (2009). Diálogos solidarios entre poetas latinoamericanos. Recuperado de http://dialnet.unirioja.es/servlet/articulo?codigo=3015339 
[...] por eso en los años veinte les tocó a los brasileños exponer y carnavalizar la musa oficial. A partir de entonces (en la obra de Huidobro y de Borges, de Oswald y Mário), resultó evidente que solo las distorsiones de la parodia y la violencia de la antropofagia podían hacer justicia al «espíritu» de la literatura latinoamericana. [...] Esas formas de carnavalización recíproca, motivadas por el conflicto de culturas heterogéneas, se convirtieron en la pauta básica de una cultura latinoamericana (Rodríguez Monegal, 1979, p. 406).

Un ejemplo de ello se puede encontrar en la revista peruana Amauta (uno de los principales órganos de divulgación y debate de los movimientos de vanguardias del continente), donde se publica un largo ensayo titulado «El redescubrimiento de América». El autor, Waldo Frank (1928, p. 1), escribe que «hemos llegado a ser nuestros propios críticos; estamos haciendo el balance de nuestro pasado». En el mismo año, Ricardo Martínez de la Torre (1928, p. 33) defiende su propia versión de dicha actitud «antropofágica», tan necesaria a nuestra supervivencia y autonomía cultural:

Las ideas son estados fotográficos de circunstancias determinadas. Estas circunstancias se transforman de igual manera que nuestra fisonomía. Lo que vive, cambia. [...] De los leaders revolucionarios, incluyendo al mismo Lenin, tomemos lo que nos sea útil. Con las ideas hemos de seguir el mismo procedimiento biológico de la nutrición. Asimilar lo asimilable. Lo que precisa nuestro organismo. Expulsar cuanto antes el excremento para no contraer una fiebre intestinal.

La primera mitad del siglo XX, en buena parte de América Latina, será marcada por dos conceptos fundamentales para la configuración de un nuevo imaginario histórico y cultural posvanguardias: la parodia y el carnaval $^{4}$. El crítico Eduardo Coutinho nos brinda el resumen de sus consecuencias artísticas e ideológicas, que tendrán en Brasil un fuerte arraigo y desarrollo:

Na expressão artística, o «desvio da norma», ou deformação, passa a ser visto como positivo, conferindo à cultura do continente uma inflexão lúdica e paródica. Nos modos de apropriação das formas estrangeiras, sejam eles sérios ou jocosos, vê-se o signo da abertura

4 El carnaval en sentido bakhtiniano, como la risa que se enfrenta al discurso jerárquico y el statu quo. También el sociólogo Octavio lanni reconoce la crítica implícita en la parodia y en la carnavalización, al afirmar que «consciente ou inconscientemente, a paródia permite carnavalizar o pensamento do outro, introduzindo-se aí um ingrediente crítico, satírico, pagão» (lanni, 1993, p. 131). Ricardo Zani completa: «O que para Bakhtin convencionou-se chamar de dialogismo ou carnavalização [...] para os modernistas brasileiros, como Mário de Andrade, denominou-se antropofagia. Considerando-se, aí, que a noção de antropofagia defendida pelos modernistas brasileiros pode ser caracterizada como uma ocorrência intertextual ou dialógica» (Zani, 2003, pp. 122-123). 
americana à recepção geradora, da sua vocação antropofágica, que converte o produto final, não em cópia, mas em simulacro destruidor da dignidade do modelo (Coutinho, 2003, p. 49).

Por tanto, aunque parte de la crítica en Brasil considere la antropofagia oswaldiana desgastada, como algo que suena «um pouco como peça de museu: desafinada, empoeirada» (Coelho, 2000, p. 221), se debe admitir, con Silviano Santiago (1982, p. 21), que fue uno de los «antídotos» culturales de fundamental importancia para el imaginario brasileño construido a partir de los años 20. También para Roberto Schwarz (2002, pp. 11-12), «Oswald de Andrade inventou uma fórmula fácil e poeticamente eficaz para ver o Brasil», que consistía en dos operaciones: «a justaposição de elementos próprios ao Brasil-Colônia e ao Brasil burguês, e a elevação do produto —desconjunturado por definição-à dignidade de alegoria do país».

Tal «ufanismo crítico» (Schwarz, 2002, p. 13) entró muy subterráneamente en el imaginario cultural brasileño, dejando su sello en una vertiente importante de su producción artística, la que busca transformar la tensión social en una marca cultural que es a la vez un problema y un hallazgo, un antídoto convenientemente utilizado para «desdramatizar» nuestras fracturas internas o «heridas coloniales» (Mignolo, 2007) ${ }^{5}$.

Este «entre-lugar» (Santiago, 1982) abre espacio a que se elabore un «pensamiento fronterizo» (Mignolo, 2007) al margen de lo hegemónico, construido como resistencia desde los inicios mismos de la conquista ${ }^{6}$. Dicho proceso encuentra en las vanguardias del continente un momento de maduración que luego se hará cada vez más constante en las dinámicas artístico-culturales contemporáneas. Dice Silviano Santiago (1982, p. 39):

É neste entrecruzar de discursos [...] que se impõe o silêncio do narrador-intelectual e que se abre a batalha da paródia e do escárnio, é aí que se faz ouvir o conflito entre o discurso do dominador e do dominado. É neste pouco pacífico entrelugar que o intelectual brasileiro encontra hoje o solo vulcânico onde desrecalcar todos os valores que foram destruídos pela cultura dos conquistadores. É aí que se constitui o texto-da-diferença.

Para concluir, traemos a colación una cita del crítico Benedito Nunes (Andrade, 1990, pp. 15-16), quien defiende que la antropofagia es nada más que nuestra partida de nacimiento cultural:

5 Roberto Schwarz (2002, p. 18) afirma incluso que «talvez não seja exagero dizer que ela [a antropofagia] animou a parte crucial de nossa tradição literária».

6 Obsérvense las recientes publicaciones de varios intelectuales latinoamericanos que, desde áreas distintas, defienden que las resistencias descoloniales empiezan a la par con la violencia de la conquista. 
Como símbolo da devoração, a Antropofagia é a um tempo metáfora, diagnóstico e terapêutica: metáfora orgânica, inspirada na cerimônia guerreira da imolação pelos tupis do inimigo valente apresado em combate, englobando tudo quanto deveríamos repudiar, assimilar e superar para a conquista de nossa autonomia intelectual; diagnóstico da sociedade brasileira como sociedade traumatizada pela repressão colonizadora que Ihe condicionou o crescimento [...]; e terapêutica, por meio dessa reação violenta e sistemática, contra os mecanismos sociais e políticos, os hábitos intelectuais, as manifestações literárias e artísticas, que, até a primeira década do século XX, fizeram do trauma repressivo [...] uma instância censora, um Superego coletivo. [...] Nesse combate sob a forma de ataque verbal, pela sátira e pela crítica, a terapêutica empregaria o mesmo instinto antropofágico outrora recalcado, então liberado numa catarse imaginária do espírito nacional. E esse mesmo remédio drástico, salvador, serviria de tônico reconstituinte para a convalescença intelectual do país e de vitamina ativadora de seu desenvolvimento futuro.

\section{La vertiente antropofágica de Ferreira Gullar}

Ferreira Gullar (pseudónimo de José Ribamar Ferreira, 1930) nació en São Luiz, la capital del estado de Maranhão, departamento del noreste de Brasil. El poeta, quien llegó a disfrutar de la amistad personal de Oswald de Andrade, no podría eludir la recién inventada tradición antropofágica. Aunque muy pronto empieza a construir sus propios caminos, Gullar se deja impregnar sobre todo por la vertiente crítica de la antropofagia; menos de su risa y más de su necesidad subversora. En la primera fase de su obra reivindica (junto a los concretistas de São Paulo) dicha herencia filosófica y literaria 7 . Pero de una manera general la orientación antropofágica se convierte, en su poesía, en palabra de denuncia y ataque, a veces muy dura y corrosiva, siempre lista para contraatacar el statu quo, la política como poder que aplasta al ser humano, tanto en sentido colectivo/ social como subjetivo/individual. Veamos, como ejemplo, el poema «A bomba suja», en el cual sitúa «as palavras reais» (pp. 5-8), entre la ingenuidad de la palabra lírica que se ausenta de su contexto histórico-social y aquella excesivamente cargada de sus idiosincrasias. El mundo, con toda su complejidad, se introduce en la poesía (Gullar, 1983, p. 218):

\footnotetext{
7 Ferreira Gullar reconoce el valor de Oswald de Andrade y su importancia en la tradición literaria y cultural brasileña en el homenaje que le hace en el poema «Oswald morto», de $O$ vil metal (1954-1960). La primera estrofa dice: «Enterraram ontem em São Paulo / um anjo antropófago / de asas de folha de bananeira / (mais um nome que se mistura à nossa vegetação tropical)». En el poema, Oswald se convierte en un ser híbrido, entre el ángel y el banano, que sobrevuela e inspira la escena cultural de Brasil.
} 
Quem fala em flor não diz tudo.

Quem me fala em dor diz demais.

O poeta se torna mudo

sem as palavras reais.

La palabra poética es, por tanto, la unidad relacional por excelencia entre tantas instancias: lo individual y lo colectivo, la alegría y el dolor, como al final de este mismo poema «A bomba suja», de clara afinidad con la poesía de protesta; pero en la última estrofa vemos el poema como un artefacto capaz de enlazar hambre y esperanza:

\section{E sobretudo é preciso trabalhar com segurança pra dentro de cada homem trocar a arma da forme pela arma da esperança. (Gullar, 1983, p. 218).}

En esta geografía temporal intermediaria se mueve el poeta maranhense: entre el tiempo solitario y el solidario (Turchi, 1985). Ferreira Gullar busca enlazar los dos extremos de su concepción lírica, que es, también, existencial.

En un primer momento, su trayectoria parte de la búsqueda incesante por la transformación del hombre y la poesía a través del lenguaje, para luego alcanzar una experiencia muy particular de «conversión» que lo inserta definitivamente en el tiempo histórico y social que le tocó vivir. Ferreira Gullar, que empieza incorporando la vida al lenguaje de tal manera que el mismo cuerpo se funde a la experiencia poética, afirma: «fugi pela poesia, inventei um mundo feérico e feroz. Um suicídio esplendente: ateei fogo ao verbo, minhas vestes mortais, como se fosse meu corpo» (Gullar, 2006, p. 142). El cuerpo, por tanto, se funde a la palabra y viceversa: «[...] trabalhar a linguagem é trabalhar o homem, e o poema torna-se desse modo um corpo novo em que o homem se constrói, melhor» (Gullar, 2006, p. 162).

En este proceso, se recrea en secuenciadas experiencias de ruptura que siempre tiene en el lenguaje su punto de partida y de llegada. Es la muerte el primer paso para la renovación de la vida:

A literatura, que me prometia uma resposta para o enigma da vida, lembrava-me a morte, com seu mundo de letras pretas impressas em páginas amarelecidas. Compreendi que a poesia devia captar a força e a vibração da vida ou não teria sentido escrever. Nem viver (Gullar, 2006, p. 148). 
Así, vemos en el poema «A poesia» un ejemplo de su defensa de la importancia de la palabra poética, palabra-puente capaz de unir el hombre y la sociedad, lo particular y lo colectivo, siempre a través del lenguaje:

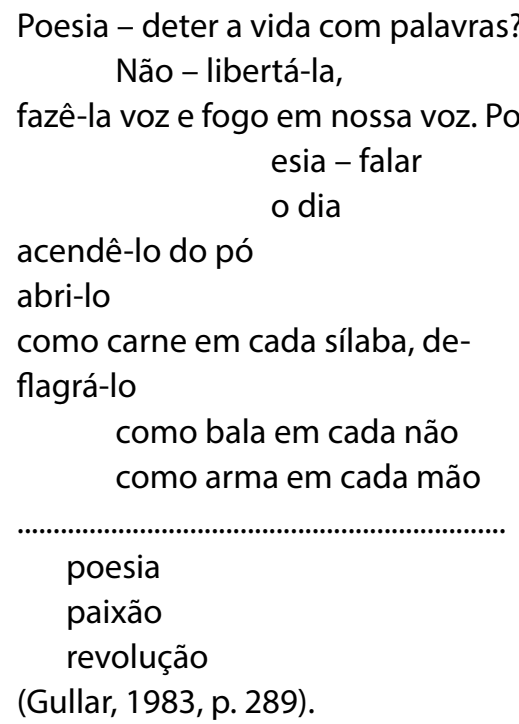

Las tres palabras que cierran este poema forman una gradación que va del sentimiento más íntimo y subjetivo - poesía y pasión- a su explosión colectiva: la revolución. En otras palabras, la revolución es también poesía y pasión en cuerpo colectivo, en ámbito social.

En «A voz do poeta», Gullar (1983, p. 395) afirma que la poesía:

Não é voz de passarinho

flauta do mato

viola

Não é voz de violão

clarinete pianola

É voz de gente

(na varanda? na janela?

na saudade? na prisão?)

é voz de gente - poema:

fogo logro solidão

Nuevamente el poema se cierra con tres palabras que intentan definirlo: fuego, logro y soledad. En esta nueva versión (o tentativa metapoética), dichas palabras guardan la misma carga semántica que las anteriores, y fácilmente podrían ser asociadas: fuego-pasión; logro-revolución y poesía- 
soledad, formando, entonces, la tríada basilar de su imaginario poético, donde poesía es lo que conmueve (Turchi, 1985, p. 113), es decir, lo que quema (fuego) tanto el ámbito sentimental como social a través de la pasión o de la revolución, pero que solo se conquista en la profunda soledad que exige el encuentro con la palabra poética o con uno mismo.

En una entrevista a la revista Poesia Sempre, Gullar (2004, p. 17) concluye: «o poema tem que ser um relâmpago. Ele tem que iluminar a tua cara, bater na tua cara como uma coisa vital». Toda esta concepción lírica converge en el poema «Traduzir-se», de Na vertigem do dia (1980), donde el diálogo es la única salida para un yo poético y biográfico que siempre buscó conciliar las dicotomías de dentro y de fuera, de lo individual y lo colectivo, de lo personal y lo histórico:

Uma parte de mim

é multidão;

outra parte estranheza

e solidão.

Uma parte de mim

pesa, pondera;

outra parte

delira.

Uma parte de mim

é só vertigem;

outra parte,

linguagem.

Traduzir uma parte

na outra parte

- que é uma questão

de vida ou morte -

será arte?

(Gullar, 2001, p. 335).

Complementariamente, Gullar (2006, p. 160) afirma que: «Quis fazer dele [o poema] a expressão desse drama, o ponto de ignição onde, se for possível, alguma luz esplenderá: uma luz da terra, uma luz do chão - nossa».

La experiencia abisal de enfrentarse al lenguaje, vivida en A luta corporal (1975), se amplía por la necesidad de actuación del poeta que quiere 
unir, definitivamente, vida y arte $^{8}$. Pero la experiencia vivida de encontrarse frente a frente con el desafío del lenguaje jamás será olvidada; al contrario, lo llevará a la vivencia de una nueva experiencia, la de sumarse a las vicisitudes colectivas y, por ende, encontrarse a sí mismo en otras voces ajenas.

Penetrar lo colectivo lo llevará a vivir una suerte de «conversión» política que, de hecho, se venía gestando a través de las lecturas de Marx y «do esgotamento da experiência de vanguarda»; este proceso llega a su ápice cuando se traslada a la capital del país, Brasília ${ }^{9}$. En este contexto, tal experiencia adquiere un sentido fuertemente nacionalista: descubrirse brasileño equivale a situarse en un determinado contexto político-social. Afirma el poeta: «eu nasci brasileiro, virei estrangeiro e comecei a virar brasileiro de novo» (Gullar, 2004, p. 30).

No obstante, lo colectivo no se traduce solamente en términos políticos, sino en la cotidianidad presente en la vida simple del brasileño de a pie:

[...] a história humana não se desenrola apenas em campos de batalha e nos gabinetes presidenciais. Ela se desenrola nos quintais, entre plantas e galinhas; nas ruas de subúrbios, nas casas de jogo, nos prostíbulos, nos colégios, nas ruínas, nos namoros de esquina (Gullar, 2006, p. 142).

Como consecuencia, el enfrentamiento entre la materia del mundo y la materia poética promueve el diálogo que encontrará un cauce seguro para su producción literaria, ya definitivamente compuesta como un profundo canto solidario:

Disso quis eu fazer a minha poesia, dessa matéria humilde e humilhada, dessa via obscura e injustiçada, porque o canto não pode ser uma traição à vida, e só é justo cantar se o nosso canto arrasta consigo as pessoas e as coisas que não têm voz (Gullar, 2006, p. 142).

Ferreira Gullar (2006, p. 159) reconoce que «é da própria natureza da arte romper os limites da solidão, ainda que seja abismando-se nela, transcendendo-a por baixo». La soledad poética, esta lucha corporal con las palabras, se va haciendo, poco a poco, su medida de interacción con los otros y, por tanto, con la sociedad. Tras sumergirse profundamente en

8 Sobre el libro A luta corporal, Eleonora Camenietzki afirma: «Ainda vasculhando as possibilidades do discurso, mastigando a sintaxe, explodindo o verso e as palavras, e experimentando novas formas de ocupar o espaço em branco, o poeta demarca suas obsessões principais e os temas centrais em que trabalhará ao longo da vida: o tempo, a linguagem e a identidade» (Camenietzki, 2001, pp. 144-145).

9 Obsérvese que la primera lectura marxista de Gullar tiene una orientación religiosa, ya que se da a través del libro La pensé de Karl Marx, de un padre llamado Yves Calvez. En una entrevista, Gullar afirma que «o padre me converteu ao marxismo» (Gullar, 1989, p. 132). 
una suerte de existencialismo lingüístico (en A luta corporal), Gullar llega a la base sobre la cual construirá toda una nueva visión poética: el encuentro con lo humano que hay en uno mismo y en su entorno; la percepción de que ambas las instancias - el yo y el otro- tienen que coexistir:

O poeta fala dos outros homens e pelos outros homens, mas só na medida em que fala de si mesmo, só na medida em que se confunde com os demais. Depende, portanto, de sua personalidade — do grau de abertura dessa personalidade com respeito à sua época, com respeito à vida que se vive à sua volta, do modo como relaciona seus problemas e sentimentos aos problemas e sentimentos dos outros homens- o caráter de sua poesia (Gullar, 2006, p. 158).

La poética de Gullar traza sus versos entre el optimismo idealista y la profunda crítica que nace cuando se enfrenta a la realidad (social o lingüística). Afirma que su hábitat natural debe ser el mismo de todos los hombres:

É inevitavelmente uma parte minúscula destes dias vertiginosos e frequentemente cruéis que vivemos. Talvez por isso não seja uma poesia doce e alada, mas áspera e suja, que não se quer valer de nenhuma ilusão mas que, sob a noite e a lama, não renuncia à esperança, uma mínima esperança (Gullar, 2006, p. 159).

Se trata, pues, de una clara filiaciación a la poesía impura nerudiana, escrita «sob a noite e a lama», pero que jamás renuncia a ser un canto utópico, un canto de esperanza.

\section{Gullar y Cisneros: de impurezas y tensiones}

La imagen del barro (lama) $-y$, por extensión, de la podredumbre-, siempre tan presentes en la obra de Gullar, es, también, una imagen bastante recurrente en la obra del peruano Antonio Cisneros (1942-2012), cuya poética se levanta sobre un amplio bestiario, y donde el barro se asocia al chancho; esta fuerte imagen que llega a representar al poeta mismo en su poema "Arte poética», incluido en Como higuera en un campo de golf, de 1972:

UN CHANCHO hincha sus pulmones bajo un gran limonero mete su trompa entre la Realidad se come una bola de Caca

eructa pluajj un premio 
2

Un chancho hincha sus pulmones bajo un gran limonero mete su trompa entre la Realidad

- que es cambiante-

se come una bola de Caca

— dialécticamente es una Caca Nueva-

eructa

—otra instrumentación-

pluajj

otro premio

3

Un chancho etc.

(Cisneros, 1989, p. 123).

Poema bastante complejo, que satiriza la realidad a través de la ironía a los discursos que se hacen sobre esta misma realidad (obsérvense las mayúsculas que nivelan la «Realidad» y la «Caca», además de todo un vocabulario filosófico puesto en estricto diálogo con la «Caca», aquí también representante del barro y la suciedad del mundo a que se refiere Gullar).

En «Arte poética» el chancho es el mismo poeta que, antropofágicamente, produce sus premios, los poemas, a través de la digestión de esta «Realidad» que es la «Caca» o el mundo. Como lo afirmo en otro texto:

Antonio Cisneros llega al borde de una irreverencia grotesca y, al desmontar la figura clásica del poeta —este poeta descrito por movimientos anteriores como siendo capaz de trasmutar y trascender la Realidad-, pone en jaque un pilar fundamental de la escritura contemporánea en América Latina: el papel social y ontológico del poeta. Pero, por otro lado, confirma su acción en el plano de la realidad tanto literaria y filosófica como humana, ya que no busca destruir la imagen del poeta trasmutador de la realidad, pues al intentar ridicularizarla, la invierte $y$, en un sentido opuesto, la reafirma. El poeta es un chancho que se alimenta de una Realidad escatológica y, aún así, produce sus premios. Si la realidad ha cambiado, el escritor también tiene que cambiar su relación con ella. La ironía va hacia la Realidad y los diversos discursos que se hacen sobre ella. El poeta es, claro está, su víctima y a la vez el verdugo de tantos discursos (Pereira, 2004, p. 1389).

Según el crítico Alcides Villaça, en la obra de Gullar, de una manera general, «o mundo surge como fonte impura dos múltiplos tumultos que assaltam o sujeito poético; a vingança deste está em processá-los no interior da consciência irônica - consciência de fato idealizante, em sua busca de 
um metal verdadeiro» (Villaça, 1998, p. 96). Poetas de una alquimia contemporánea, Cisneros y Gullar encuentran en la basura y en los escombros históricos de sus países un tesoro existencial, político y poético de clara filiación descolonial.

En el poema «Agosto 1964», del poeta brasileño, el barro (lama) está metafóricamente expresado en los elementos que van configurando el ambiente de la dictadura militar en el cual se introduce la voz poética, y en el sentido nostálgico y sofocante que encauza la escritura de los versos. Este poema podría ser, también, un arte poética del autor o una suerte de testamento lírico:

Entre lojas de flores e de sapatos, bares, mercados, butiques, viajo

num ônibus Estrada de Ferro - Leblon.

Volto do trabalho, a noite em meio, fatigado de mentiras.

O ônibus sacoleja. Adeus, Rimbaud, relógio de lilases, concretismo, neoconcretismo, ficções da juventude, adeus, que a vida eu a compro à vista aos donos do mundo.

Ao peso dos impostos, o verso sufoca, a poesia agora responde a inquérito policial-militar.

Digo adeus à ilusão mas não ao mundo. Mas não à vida, meu reduto e meu reino.

Do salário injusto, da punição injusta, da humilhação, da tortura, do terror, retiramos algo e com ele construímos um artefato um poema uma bandeira. (Gullar, 1983, p. 233).

Es notoria la sintonía de tonos e imágenes que mueve las poéticas de Cisneros y Gullar. Entre la crítica y la ironía, ambos se sumergen en la realidad grotesca donde está inmersa tanto la vida individual como la colectiva, en un continente plagado de crisis históricas y sociales. Los poemas 
- reelaboraciones utópicas, signos en rotación en constante diálogo con el mundo- responden a la necesidad histórica de América Latina, de sobreponerse a la dura realidad a través de pequeñas dosis de esperanza ${ }^{10}$.

Como consecuencia se genera una poética polifónica, en la cual el yo poético se vuelve un instrumento solidario, cada vez menos solitario, ya que por él hablan muchas otras voces. En este sentido, la siguiente afirmación de Maria Zaira Turchi respecto a Gullar, también nos ayudaría a leer la poética cisneriana:

As vozes na lama, captadas por Gullar, não apenas fazem reviver as angústias metafísicas do poeta solitário, mas o fazem portador de nova mensagem como intérprete, poeta solidário, dos que, em silêncio, vivem na lama, submissos e resignados à sua vida sub-humana (Turchi, 1985, p. 127).

Asimismo, Cisneros y Gullar podrían ser considerados poetas de un pesimismo activo; con el tiempo transformaron el sueño juvenil de la transformación social rápida y radical que les daba aliento en la década de 1960, en reflexión crítica y muchas veces corrosiva, labrada con la madurez de las vivencias políticas en sus contextos. Para ambos poetas, ninguna mitología o teología es más importante para su labor de escritura que la misma materia del mundo: «O poeta moderno, sem mitologia e sem teologia, não habita o Parnaso nem se sente tocado pela graça: caminha no chão do asfalto da cidade e tenta transformar em canto a matéria vulgar do cotidiano» (Gullar, 1989, p. 8).

También como Cisneros, Gullar cree que es esta materia vulgar fuente de riqueza literaria y existencial. Obsérvese el mismo título del poema «Homem Comum»:

Sou um homem comum

de carne e de memória

de osso e esquecimento.

Ando a pé, de ônibus, de táxi, de avião

e a vida sopra dentro de mim

pânica

feito a chama de um maçarico

e pode

subitamente

cessar.

10 Nótese que la antología poética de Ferreira Gullar publicada en Lima cuenta con la traducción de Antonio Cisneros. Gullar, F. (1987). Poemas. Lima: Embaixada de Brasil. 


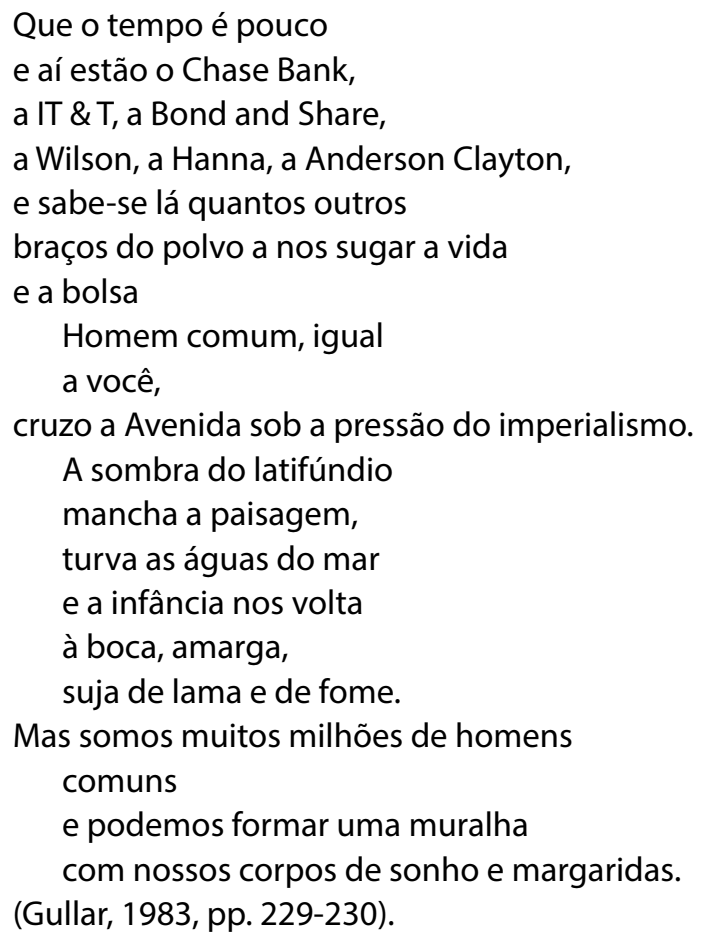

Gullar reconoce el sentido opresor de las grandes instituciones y las ve desde la perspectiva del «hombre común». Nuevamente el barro surge para recordarle la infancia y su real condición de hombre común; reconocimiento que es a la vez corporeo, físico, sensitivo: un dato afirmado por la conciencia, pero sobre todo por su propio cuerpo. O, como afirma Eleonora Ziller Camenietzki (2004, p. 54) «é a materialidade do corpo que produz o pensamento e as palavras. É este corpo biológico que se desdobra num corpo-texto múltiplo, inesgotável e transcendente.»

También el tono cronístico del poema (como una crónica del cotidiano), lo acerca aún más a Antonio Cisneros. Cisneros, como Gullar, es el observador crítico de una realidad con la cual no se conforma; pero ambos poetas no admiten otra forma de actuar que no la lingüística o literaria. Esa es su arma de acción y de intervención. Para concluir, afirma Gullar (2006, p. 152):

Pretendo que a poesia tenha a virtude de, em meio ao sofrimento e ao desamparo, acender uma luz qualquer. Uma luz que não nos é dada, que não desce dos céus, mas que nasce das mãos e do espírito dos homens. 


\section{REFERENCIAS BIBLIOGRÁFICAS}

Andrade, O. de. (1990). A utopia antropofágica. São Paulo: Globo.

Camenietzki, E. Z. (2001). Poesia e política: A trajetória de Ferreira Gullar (tesis de doctorado). Universidade Federal do Rio de Janeiro, Río de Janeiro.

Cisneros, A. (1989). Por la noche los gatos (1961-1986). México D. F.: Fondo de Cultura Económica.

(1991). Las inmensas preguntas celestes. Madrid: Visor.

Coelho, T. (2000). Guerras culturais. São Paulo: Iluminuras.

Coutinho, E. (2003). Literatura comparada na América Latina. Río de Janeiro: UERJ.

(2001) Fronteiras imaginadas: Cultura nacional, teoria internacional. Río de Janeiro: Aeroplano.

Frank, W. (1928). El redescubrimiento de América. Los últimos días de Europa. Amauta, 2(2), pp. 1-2.

Gullar, Ferreira. (1983). Toda poesia (1950-1980). Río de Janeiro: Círculo do Livro.

(2001). Toda poesia. Río de Janeiro: José Olympio.

(1999). Muitas vozes. Río de Janeiro: José Olympio.

(2002). Cultura posta em questão. Vanguarda e Subdesenvolvimento. Río de Janeiro: José Olympio.

(1998). Cadernos de literatura brasileira. Río de Janeiro: Instituto Moreira Salles.

(1989).Indagações dehoje. Río de Janeiro: JoséOlympio.

(2004). O poema tem que ser um relâmpago. Entrevista a Luciano Trigo. Poesia Sempre, 2(18).

(2006). Sobre arte. Sobre poesia (uma luz no chão). Río de Janeiro: José Olympio.

lanni, O. (1993). O labirinto latino-americano. Río de Janeiro: Vozes.

Martínez de la Torre, R. (1928). Polémica y acción. Revista Amauta, III(16), p. 33.

Mignolo, W. (2007). La idea de América Latina. La herida colonial y la opción decolonial. Barcelona: Gedisa.

Pereira, D. A. (2002). A obra poética de Antonio Cisneros. Da tradição aos diálogos híbridos (tesis de maestría). Universidade Federal do Rio de Janeiro, Río de Janeiro. 
(2003). A poética transgressora de Antonio Cisneros. Revista Cult (66), pp. 12-13.

(2004). Antonio Cisneros: poesia-crônica (ou vice-versa). Revista ET CETERA.

(2004). Entre el escenario artístico y el histórico: las Artes Poéticas de Antonio Cisneros. En Memorias de JALLA 2004 (pp. 13871400). Lima: Universidad Nacional Mayor de San Marcos y Jornadas Andinas de Literatura Latinoamericana.

Rodríguez Monegal, E. (1979). Carnaval-Antropofagia-Parodia. Revista lberoamericana, 45(108-109), pp. 401-412.

Santiago, S. (1982). Vale quanto pesa. Río de Janeiro: Paz e Terra.

Schwartz, J. (1983). Vanguarda e cosmopolitismo. São Paulo: Perspectiva.

(1995). Vanguardas latino-americanas. São Paulo: Editora da Universidade de São Paulo.

Schwarz, R. (2002). Que horas são? São Paulo: Companhia das Letras.

Turchi, M. Z. (1985). Ferreira Gullar: a busca da poesia. Río de Janeiro: Presença.

Zapata, M. A. (Org.). (1998). Metáfora de la experiencia: la poesía de Antonio Cisneros. Ensayos, diálogos y comentarios. Lima: Fondo Editorial de la Universidad Católica del Perú. 